\title{
The 'Infrastructure Turn’ in Australian Metropolitan Spatial Planning
}

Published as: Dodson, J. (2009). "The 'Infrastructure Turn' in Australian Metropolitan Spatial Planning."

International Planning Studies 14(2): 109-123.

Jago Dodson, Urban Research Program, Griffith University.

c/- Urban Research Program,

Griffith University - Nathan Campus,

Kessels Rd, Nathan,

Brisbane, QLD 4102,

AUSTRALIA

Email: j.dodson@griffith.edu.au

\begin{abstract}
This paper argues that a recent resurgence in Australian spatial planning has been superseded by a resort to infrastructure to address urban problems. The paper uses case studies of the Melbourne and South East Queensland (Brisbane) metropolitan regions to chart the renewal of new spatial planning, after a period of neglect. This paper then shows this spatial planning renewal has given way to a new emphasis on urban infrastructure planning as the primary mode of intervention in these cities. The infrastructure turn raises important questions about the spatial planning and infrastructure of cities within a new era of global strategic challenges.
\end{abstract}

\section{Introduction}

Over the past two decades scholars have reported significant shifts in the purpose and practice of metropolitan spatial planning as a response to processes of spatial restructuring in urban regions (Salet et al. 2002). One such transition was that from urban managerialism to urban entrepreneurialism (Harvey 1989). A further shift that has been extensively debated is the emergence of spatial strategy making over older models of land-use blueprinting or spatial planning (Albrechts et al. 2001; Madanipour et al. 2001; Healey 2004). Others have argued that we have seen a phenomenon of 'splintering urbanism' emerging in many city regions resulting from fragmented governance and private management of infrastructure under globalised neoliberal conditions (Graham and Marvin 2001).

Australian cities experienced extensive spatial restructuring during the past two decades (Baum 1997) and since the late-1990s have seen a revival of interest in metropolitan planning and plan making from which new strategic planning documents have emerged 
(Gleeson et al. 2004). The uniformity of this resurgence across Australia's major cities seemed to suggest a new period in which strategic urban spatial planning had achieved a new significance, in parallel with developments elsewhere (Healey 2004). There is evidence, set out in this paper, that since the mid-2000s this revived interest in greater metropolitan strategic oversight is being replaced by a vigorous new emphasis and focus on large-scale urban infrastructure as a solution to urban problems. While the crop of new Australian metropolitan spatial plans of the 2000s remains in effect the significance of their spatial coordinating function has withered in favour of a surge of new urban investment schemes that emphasise large, complex and fiscally demanding infrastructure projects. There has been a weakening of the influence of planning agencies in shaping metropolitan policy, in favour of infrastructure departments and ad-hoc engineering project 'investigations'. In addition there has been a very recent intensification of national interest in urban issues, but in contrast to previous sporadic national-scale efforts the current raft of Federal urban initiatives is largely devoid of land use considerations; instead urban infrastructure projects will form the overwhelming bulk of the new Federal engagement.

The softening and shift away from strategic spatial planning has been sufficiently consistent across Australian cities that it can be considered to mark a new 'infrastructure turn' in Australian urban planning. The 'infrastructure turn' raises considerable questions for urban scholars about the role of land-use planning in contemporary Australian cities, and in turn, for cities elsewhere. Such questions range from identifying the potential risks - and potential benefits - of conceiving and planning metropolitan areas primarily through an infrastructure frame, to asking whether infrastructure projects alone can perform the broader strategic spatial functions of planning, such as the achievement of socially equitable and environmentally sustainable cities? Might Australian cities be witnessing a new mode of urban planning characterised by 'spatial engineering'? If this is the case what might the wider consequences be for cities elsewhere and for our new understanding of spatial planning and spatial strategy making?

At a more fundamental level, pace Graham and Marvin (2001), are questions about the longer term consequences for the urban coherence of cities from an infrastructure focus. Australia is by no means the only jurisdiction where intensive and accelerating infrastructure development is taking place. Understanding the Australian shift away from a broader, and arguably more nuanced, conception of metropolitan planning as a spatial strategy may offer insights for cities and urban regions in other nations. Further questions may be posed, pace Flyvbjerg et al. (2003), as to whether an urban spatial planning approach dominated by individual infrastructure megaprojects can alone address such pressing new challenges for cities as climate change and declining petroleum security (Atkinson 2007; Dodson and Sipe 2007). Rather than a set of individual component megaprojects perhaps we are now entering an era of the city as a constellate infrastructure 'giga-project'. What might the emergence of such an awesome new urban entity imply for urban - and global - sustainability?

This paper poses three questions about the current Australian 'infrastructure turn'. First what evidence can be assembled to demonstrate that there has been an infrastructure turn 
in Australian urban planning?; second, what is the role and status of metropolitan planning within this new 'infrastructure age'?; and, third, what are the implications for the longer term economic, social and environmental sustainability of cities after the infrastructure surge? The response to these questions is structured in three parts. The first part provides an historical review of the literature on the relationship between urban infrastructure and metropolitan planning, with a focus on the Australian context. The paper then uses documentary and empirical cases studies of strategic spatial planning in two Australian cities - Melbourne and Brisbane - to evaluate the transition from the spatial strategy revival to the contemporary 'infrastructure turn'. The final part of the paper discusses the implications of this shift for strategic metropolitan planning, both in Australia and elsewhere. The paper does not seek a comprehensive resolution of the problems identified; rather it proffers the more modest objective of throwing new light on the influences on the evolution of planning in Australia and furthering international understanding in this area of inquiry.

\section{Infrastructure and urban spatial planning}

Most historical perspectives on general and specific instances of urbanisation incorporate an implicit understanding of the role of technical systems and infrastructure networks in shaping urban patterns. Hall's (1998; 2002) urban and planning histories have paid extensive attention to infrastructure as the technical and physical underpinning for modern urbanisation. Some cities have became renowned for their infrastructure feats, such as the hydraulic works of late- $19^{\text {th }}$ Century Paris or Los Angeles' $20^{\text {th }}$ Century freeways. Yet, as Graham and Marvin (2001) argue convincingly, urbanists have in recent decades have failed to raise and address questions about the role of infrastructure in debates about urbanisation in favour of broader political, economic, social or environmental concerns. All too frequently, they charge, analyses of urbanisation have tended to downplay the often intimate, complex and intense relationships between urban patterns and constituent infrastructure. Following Winner's (1980) query as to whether 'artifacts have politics' a growing body of work has shown that large technical systems and the practices surrounding them are rarely socially neutral fabrications (Abram 2005). Star (1999), for example, argues that infrastructure is a category that is subject to the same biases as other socially constituted typologies. Because infrastructure in the form of hydraulic, energy and transport networks typically forms the essential 'connective tissue' of a city some argue these networks should be conceived as a component of a greater and often more complex urban 'socio-technical' system (Tarr and Dupuy 1988). This system may involve more than simply the use of technical networks; multiple arrays of socially complex practices, interactions, relationships, dependencies and interactions within and through infrastructure pervade contemporary urban life.

The recent recognition of the significance of infrastructure in constituting and facilitating urban life has produced a resurgence in attention from urbanists investigating the economic (Torrance 2008), social (Graham 2000) and cultural (Kaika and Swyngedouw 2000) role of infrastructure within cities. Yet, despite this renewed interest in the role of urban infrastructure in shaping urban conditions there have been relatively few attempts 
to re-inscribe this new appreciation upon metropolitan spatial planning thought or practice, or on spatial strategy making. This may be because the new attentiveness to the wider significance urban infrastructure has emerged outside of planning inquiry, in fields such as socio-cultural geography and architecture (Graham and Marvin 2001), theoretical sociology (Gökalp 1992; Coutard 1999), anthropology (Star 1999) or critical social history (Tarr and Dupuy 1988). Planning has had relatively sketchy contact with this literature and until recently there have been few attempts to assess what these perspectives offer for the management and coordination of metropolitan systems. Graham and Marvin's (2001) landmark work is perhaps closest to urban planning in its scope and intent but their emphatic charting of the collapse of universal models of infrastructure under the onslaught of neoliberal globalisation, combined with relatively modest proposals for redressing this failure, suggests little confidence that planning might regain its modern urban coordination role. Likewise, McFarlane and Rutherford (2008) view contemporary infrastructure practices as contributing to 'fragmentation, inequality and crisis in the urban fabric' (p. 364). In another vein Flyvbjerg's (2003; 2005) technical planning analyses of urban infrastructure megaprojects have vividly illuminated the internal contradictions of urban infrastructure decision making practices, under broader conditions similar to those described by Graham and Marvin (2001). Regrettably Flyvbjerg has had much less to say about how infrastructure megaprojects intersect with their wider urban contexts or superordinate practices of spatial strategy and metropolitan planning than he offers on questions of project appraisal and evaluation. Infrastructure megaprojects may often defy rational calculation but this recognition should not prevent spatial strategists from seeking to comprehend their effects on the spatial order of cities.

The problems identified by Graham and Marvin (2001), Flyvbjerg (2003), McFarlane and Rutherford (2008), among others, indicate the need for a re-assertion of spatial planning as a strategic practice of intervention, management and coordination within urban regions. Questions of urban governance under urban spatial restructuring have received considerable attention in recent years (Lefevre 1998; Brenner 1999; Kearns and Paddison 2000; Mitchell-Weaver et al. 2000; McGuirk 2003) and have often been accompanied by questions about the capacity and deficits of spatial planning (Mees 2000; Paterson 2000; Sandercock and Friedman 2000) or spatial (McGuirk 2005; Healey 2006b) strategy. While Healey (2006a) has called for a new strategic spatial planning 'imaginary', perhaps what spatial planning also needs is to re-examine and re-imagine its relationship to urban infrastructure and the contexts in which technical infrastructure decisions with urban spatial consequences are made. The remainder of this paper explores this problem of the intersection of spatial planning, spatial strategy and infrastructure in the Australian context, via two Australian case studies - Melbourne and Brisbane/South East Queensland - of contemporary spatial planning at the level of the city-region set within an historical frame. In this context spatial planning is treated as the strategic determination and spatial allocation of land-uses at the metropolitan scale. Or as Healey et al (1999, p. 341) have termed it, "a set of governance practices for developing and implementing strategies, plans, policies, and projects, and for regulating the location, timing and form of development”. These case studies, while inevitably locally detailed nonetheless reveal the fragile nature of the revival of spatial planning in some cities, especially outside Europe. While not directly intended as a counterpoint to the more 
successful European experience of spatial renewal these case studies reveal some of the contemporary tensions between spatial planning and infrastructure project development. In this vein they offer a valuable international contrast to the European perspective and demonstrate the faltering potential of a spatial planning revival in (post-) neoliberal cities.

\section{Land-use planning and the infrastructure turn in Melbourne}

\section{Land-use planning in Melbourne}

Melbourne is Australia's second largest city with a population of 3.47 million in 2006 (ABS 2008). Melbourne ably illustrates the 'infrastructure turn' in planning because this transition was preceded by a period where land-use planning became the dominant and prominent mode of government spatial strategy. This period was then followed by a gradual increase in the significance of infrastructure, culminating in a new phase in which the scale, extent, cost and efficiency of urban infrastructure became the primary concern of government planning policy.

Melbourne has a long history of urban planning dating back to 1891 when the Melbourne Metropolitan Board of Works was established to oversee the development of works and services in the colonial city. The Board's role expanded in the post-WWII era to also encompass strategic planning, parks, freeways, bridges and environmental monitoring (Williams 1999). The MMBW was abolished in the early-1990s as the rolling introduction of new public sector governance models within the Victorian state and local government combined with a regime of urban corporate liberalism (Gleeson and Low 2000) and greater interest in integrated environmental planning. The Board had already lost some of its powers by this time with Nankervis (1996, p. 65) noting that "by the mid 1980s the engineering based planners at the MMBW had given way to 'real' planners now located in their own ministry”. This period 1992-1999 was marked by a Liberal (i.e. conservative) Party State government which achieved pronounced national prominence for its energetic neoliberal agenda (Alford and O'Neill 1994; Costar and Economou 1999). Two key plans emerged from these transformations in Melbourne's urban governance: the planning strategies Living Suburbs and Transporting Melbourne were created in 1995 while a new agency in the form of the Department of Infrastructure was formed to accompany the Ministry of Planning and Environment.

Living Suburbs was an example of the Australian spatial planning reaction to the emerging imperatives that pressed upon globalising city regions in many nations in the 1990s. The main objectives of the plan included a mix of externally and internally oriented goals that would both connect the city to the global economy while making it a more attractive site for global capital (Williams 1999). These included: generating a business environment for long-term growth; building Melbourne's global transport and communications links; enhancing the city's environment and liveability; and achieving greater functionality in infrastructure management. Yet the corporate liberal political 
context weakened Living Suburbs in practice. There was little directive oversight of spatial land-uses; unlike its predecessors Living Suburbs lacked any activity or district centres policy. Commentators were scathing:

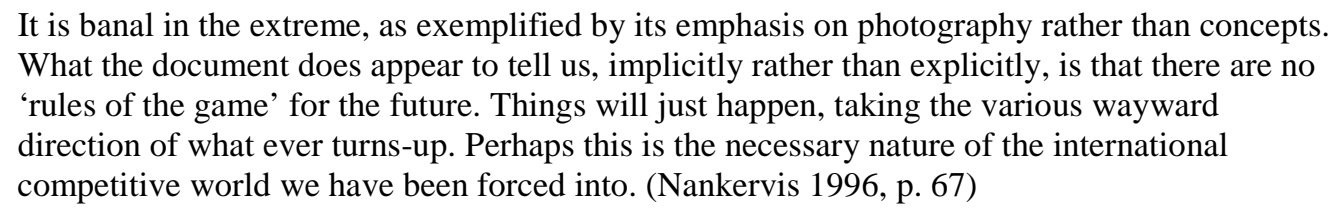

The failure to direct spatial development encountered difficulties where it intersected with rapid employment growth and continuing market driven redevelopment of Melbourne's Central Business District and inner suburbs and the broader shift among Australian cities to urban 'consolidation'. Intensified residential and commercial development was occurring in these areas but Living Suburbs' lack of directive control over development location combined with a permissive approach to the design of the built form placed developers of higher density land-uses in conflict with existing residents. This friction was greatest in the affluent 'leafy' suburbs of Melbourne's inner east, where the occupants of single-storey detached houses took umbrage at the ingress of new multi-storey apartments (Lewis 1999). Resident action groups formed to fight these planning policies and proved a persistent irritant to the Liberal state government.

\section{Renewing urban spatial strategy: the Melbourne 2030 plan}

A Labor State government was installed in 1999 on a platform that included the promise of a new metropolitan plan for Melbourne. In October 2002 the new government released the Melbourne 2030: Planning for Sustainable Growth metropolitan strategy (Department of Infrastructure 2002). This strategy was significant because of its public prominence in re-elevating land-use coordination as a primary spatial planning objective, echoing a resurgence of spatial planning already apparent in European jurisdictions (Healey et al. 1999). The plan contained two major land-use strategies. The first was an 'urban growth boundary' imposed to protect the city's ‘green wedges' and rural perimeter from urban encroachment by constraining future development within this limit (Buxton and Goodman 2003). The second key land-use approach was to concentrate spatial development within a constellation of 112 'activity centres' of varying scale and mix scattered across the metropolis, with many located on major public transport nodes.

The plan was lauded by many commentators who saw it as a revival of land-use planning in a new era of spatial strategy making, but the measures the scheme introduced have proven extremely controversial in Melbourne. Criticisms have typically taken two forms. First, some commentators suggest the land-use planning components of the plan are insufficiently robust to meet their objectives (Dodson 2003; Mees 2003; Birrell et al. 2005; Goodman and Coote 2007). Others have argued that the limits on urban expansion and the promotion of activity intensification have been excessive while the approach to denser urban form has been too permissive (Birrell et al. 2005). 
In addition to its prominent land-use components the Melbourne 2030 plan was also significant for its weak treatment of urban infrastructure, especially transport networks (Dodson 2003; Mees 2003; O'Connor 2003). None of the twelve technical reports prepared to support the plan considered infrastructure nor was there specific discussion of infrastructure within the strategy. This absence is curious given the sponsorship of the Department of Infrastructure and the emphasis on public transport-based activity centres within the plan. It seems that the intellectual shift towards land-use planning signalled by Melbourne 2030 had crowded out thinking on infrastructure to support it.

The only major infrastructure component to be detailed in Melbourne 2030 was the Scoresby freeway in Melbourne's eastern suburbs which was conceived and approved outside of the plan preparation process. Even the Melbourne 2030 Transport implementation plan, which was released after the four main Melbourne 2030 land-use and environmental implementation plans, eschewed infrastructure commitments in favour of promises to undertake a further round of preparing tram, train and bus plans. O’Connor (2003) has suggested that the lack of infrastructure planning within Melbourne 2030 arose as a result of the recent corporatisation, privatisation and market reorientation of water, energy, and transport networks which limited planners' capacities to direct and control the development trajectory of these systems. Such problems of urban infrastructure 'splintering' (Graham and Marvin 2001) have acutely afflicted Melbourne’s public transport (Mees 2005).

\section{Excepting infrastructure}

Urban infrastructure was considered as part of a parallel but separate process undertaken outside Melbourne 2030. The Victorian government had formed an Infrastructure Planning Council (IPC) in 2001 to advise it on infrastructure policy. The IPC produced a report in August 2002 which identified a range of considerations for Melbourne's urban infrastructure (IPC 2002). The IPC report covered water, energy, transport and telecommunications but identified few specific projects and instead largely offered advice for future state government consideration. For example on transport issues the IPC recommended that the government should adopt a "holistic approach to transport infrastructure planning and delivery" (p. 51) and that it "develops and implements a more environmentally sustainable passenger transport system” (p. 58), but recommended no new projects. Most of the report's advice addressed governance and management issues thrown up by the fragmentation of infrastructure systems as a result of privatisation, such as the already apparent and now widely acknowledged performance problems in Melbourne's public transport resulting from the private franchising of the networks (Mees 2005; Kain 2007).

The Melbourne 2030 implementation process remained the subject of ongoing controversy in Melbourne. Given the land-use planning commitment to transit-based activity centres the lack of serious intention to improve public transport became the subject of considerable derision. This problem most greatly affected the new growth corridor zones where promised improvements in the coordination of land-use 
development with public transport were not occurring. The Victorian government felt forced to respond to this disquiet and in 2004 it released a new transport strategy called Linking Melbourne: Metropolitan Transport Plan (DOI 2004). While the growing significance of transport infrastructure was clearly demonstrated by the apparent need for this plan, like Melbourne 2030's transport implementation plan and the IPC report Linking Melbourne was equally devoid of serious content. Linking Melbourne largely gathered together a long list of existing piecemeal policies and projects around a transport theme but did not set out any major new projects to be pursued. As one commentator suggested the scheme was "the sort of plan governments produce when they haven't got a plan for public transport but would like to give the impression that they have" (Davidson 2005). The exceptions to this pattern were a set of major road links and bypasses within Melbourne which were listed under 'freight improvements' and for which economic valuations had also been conducted.

The continuing planning neglect of infrastructure under Melbourne 2030 became increasingly acute and a number of proposals began to emerge from outside the Victorian state government. One late-2005 review counted five different transport infrastructure plans proposed by non-government bodies as diverse as the Victorian Chamber of Commerce and Industry, the Public Transport Users Association, a group of local governments under the banner of the Metropolitan Transport Forum and a professor of transport planning (Silkstone 2005). Most of these schemes involved major investment in new rail network capacity including a range of suburban extensions and a miscellany of underground links below the Melbourne CBD.

The Victorian government again responded to this external advocacy in 2006 with a new transport scheme, Meeting Our Transport Challenges: Connecting Victorian Communities. This plan marked a significant turn in the Victorian government's thinking on infrastructure in Melbourne. For the first time in over a decade there was an urban infrastructure plan that listed a set of possible new infrastructure projects accompanied by cost estimates and approximate implementation timeframes. Public and industry pressure for comprehensive urban infrastructure planning in Melbourne was beginning to effect policy change. Yet, Meeting Our Transport Challenges was not a comprehensive

transport plan. Much of its content re-stated existing policy positions from Linking Melbourne and prior documents while the sole public transport network extension was timed to commence as late as 2016. The main innovation in Meeting Our Transport Challenges was thus the infrastructure timetable, a largely rhetorical statement that was seemingly inspired by the more detailed Infrastructure Plan recently produced for South East Queensland (see below).

\section{Bring in the engineer}

Public complaint over Melbourne's weak infrastructure planning persisted and in 2006 the Victorian government again responded by commissioning another transport plan - led by an engineer - which resulted in the 2008 Investing in Transport report (Department of Transport 2008). The main components of this scheme were two new transport links in 
the form of a 'metro' rail tunnel beneath Melbourne’s CBD and a road tunnel through the inner northern suburbs, costing an estimated $\$ 7$ billion and $\$ 5.5$ billion respectively. These were accompanied by further road and rail projects worth $\$ 5.5$ billion. In contrast to previous infrastructure plans for Melbourne this report was detailed and comprehensive and involved not merely project listings and prospective timeframes but extended to include full project investigation and analysis. Neither Linking Melbourne or Meeting Our Transport Challenges included technical assessments but Investing in Transport was accompanied by fourteen technical reports covering demographic, economic, heritage, engineering, traffic and public transport matters. In further contrast to the criticisms of the weak substantive content of Melbourne 2030's transport implementation plan, Linking Melbourne or Meeting Our Transport Challenges, the Investing in Transport plan was specific about metropolitan transport infrastructure to be constructed, its technical and broader planning significance and its economic cost and value. While some of the Investing in Transport discussion and analysis concerned landuse planning, this largely reiterated the activity centre and growth boundary elements of Melbourne 2030. Yet at the time of writing the government was reported to be considering relaxing the growth boundary and thus undermining the spatial land-use strategy. In further contrast the State was also reported as considering a new 'Transport Statement' based on the Investing in Transport plan to set out its preferred options and investment priorities. These were anticipated to include the underground rail tunnel, but not the road tunnel, as well as two outer suburban rail extensions. The further weakening of the Melbourne 2030 land-use provisions combined with the new dominating emphasis on infrastructure clearly illustrates the 'infrastructure turn' in Melbourne's metropolitan planning.

The Melbourne case is instructive because it reveals one trajectory for the 'infrastructure turn' in urban policy and metropolitan spatial planning. Melbourne's infrastructure turn began with a renewal of land-use control and coordination via a metropolitan strategy. While this approach has persisted, if weakly, its significance began to be overtaken by growing civic, industry and state anxiety about the role of urban infrastructure within Melbourne, especially transport. Gradually, but with increasing force a momentum built which resulted in a major shift towards detailed infrastructure planning for Melbourne. Concern with infrastructure now dominates anxiety about spatial strategy and land-use coordination in Melbourne and looks set to form the basis of continuing civic controversy in the city. The Melbourne case is also instructive because the transition to an infrastructure focus in metropolitan planning took place over a long time period from (at least) 2002 to 2008 and contrasts with the much more accelerated infrastructure turn in Brisbane and the wider South East Queensland region, which is examined in the next section.

\section{Urban and Infrastructure Planning in South East Queensland}

South East Queensland (SEQ) is a metropolitan region of 2.2 million residents centred on Brisbane, which is Australia's third largest city, and includes the Gold Coast City which is the nation's sixth largest. Until this decade the SEQ region did not have a metropolitan 
planning authority or agency nor was there a region-wide land-use or infrastructure plan. Rather than establishing a Metropolitan Board of Works as occurred in Melbourne infrastructure planning in SEQ had historically been delegated to large unitary local governments. The SEQ primate city of Brisbane had been unified in 1924 and assumed control over hydraulic services and tramways (buses after 1968), as well as municipal land-use planning. Similar approaches were followed in other SEQ municipalities so that each metropolitan sub-region had, for example, its own water reservoirs and reticulation networks or bus services (often managed by private operators).

The case of South East Queensland illustrates the 'infrastructure turn' in Australian urban planning because it has followed a similar, albeit accelerated, pattern to that of Melbourne over the last two decades. As in the Melbourne example SEQ initially made some halting, and then more confident, forays into spatial land-use coordination at the scale of the metropolitan region, with infrastructure a secondary concern. Strategic landuse planning was strengthened substantially at the metro-regional scale in 2005 with infrastructure planning rapidly elevated to equal status, including some gigantic transport infrastructure proposals. Since 2005 infrastructure has taken on even greater significance than land-use planning such that the Queensland government's capacity to plan and manage SEQ's metropolitan infrastructure management has become a key test of its legitimacy. During this period the region's largest local authority, Brisbane City, has also taken on a major transport infrastructure planning role which in some aspects rivals that of the State. These marked State and municipal shifts to ambitious infrastructure planning further support the case that there has been an 'infrastructure turn' in Australian urban planning.

\section{Spatial metro-regional planning in SEQ}

The presence of large unitary municipal authorities meant that metropolitan region scale land-use planning didn't emerge in SEQ until 1991 when a Regional Organisation of Councils (SEQROC) was formed from the region's 19 local governments. While it was served by a secretariat hosted by Brisbane City Council the SEQROC was a voluntary entity with no statutory authority or independent spatial planning capacity to direct or control metropolitan development. However the Queensland State government took some significant initial steps towards using this body for regional land-use coordination by setting up the SEQ2001 Regional Growth Management Project to create a Regional Growth Management Framework as a basic strategy to guide the region's spatial development (Dodson and Gleeson 2003).

The first SEQ Regional Framework for Growth Management (RFGM) was released in 1994 and underwent four revisions by 2000. The 2000 iteration of the RFGM (SEQROC 2000) covered similar planning issues to those that had emerged elsewhere in Australian metropolitan planning over the previous decades (see Gleeson 2004). These included environmental protection and management, urban growth, residential development and major centres as well as economic development and the now ubiquitous 'livability' [sic] (SEQROC 2000). Infrastructure, such as transport and infrastructure, was subsumed 
under 'urban management' within the conceptual structure of the RFGM. Some of the land-use content echoed that now common in Australian urban schemes. For example the a version of the intent to "encourage transit oriented residential development, including mixed-use development, at public transport nodes and major centres” (SEQROC 2000, p. 52 ) is common to almost every contemporary Australian metropolitan strategy. Despite the broad land-use scope of the RFGM the relatively weak institutional status of the SEQROC meant that the strategy itself lacked institutional force. The SEQROC was a cooperative body so the implementation of the RFGM relied on the cooperation of its constituent municipalities which each had their own growth management concerns and imperatives that didn't necessarily cohere with those pressing at the regional scale. The result was a strategic spatial scheme which lacked the overarching governance capacity to act strategically; metro-regional RFGM concerns continually risked being subordinated local municipal imperatives.

\section{A new regional spatial plan}

By the early-2000s SEQ's status as Australia's fastest growing metropolitan zone was stimulating civic concern that the factors that attracted residents to the region, such as a high quality environment, affordable housing and efficient urban infrastructure were being placed at risk by inadequate spatial coordination of urban growth. Pressure from community groups, media and the academic sector in favour of government action began to intensify (Gleeson 2003b; Gleeson 2003a; Low Choy 2003; Sipe and Gleeson 2003). In early-2004 the Labor State government announced that a Regional Plan would be prepared to manage the spatial development of South East Queensland under a newly established state Office of Urban Management (OUM). The eventual SEQ Regional Plan (SEQRP) (OUM 2005b) included two significant innovations. First the plan was given statutory force to compel municipalities to produce Local Growth Management Strategies that would implement the spatial objectives of the SEQRP. These spatial objectives included an 'urban footprint' (i.e. an urban growth boundary) which would limit urban spatial expansion in combination with a centres and concentration program that included numerical targets for population accommodation by local government zones. Second, and significantly for the thesis of this paper, the SEQRP was accompanied by a parallel SEQ Infrastructure Plan and Program (SEQIPP) (OUM 2005a) which would not only identify the specific infrastructure projects to be undertaken by 2026 but also included cost estimates and planning and construction timeframes. The OUM planners, it seemed, had observed the civic consternation over the lack of substantive infrastructure content in the recent Melbourne 2030 strategy and sought to ensure this criticism could not be easily levied against the SEQRP. The inclusion of a detailed infrastructure plan further supports the view that there has been an 'infrastructure turn' in Australian metropolitan planning.

The SEQIPP marked a distinctive shift in the approach to metropolitan infrastructure planning in Australian cities. The SEQIPP covered not only the usual transport, energy and water components found in other Australian cities' cognate schemes but extended to include communications and IT networks, as well as some social infrastructure, such as hospitals and schools needed to support projected population growth. A feature of the 
plan was the presentation of detailed tables for each of the SEQ sub-regions with a specific list of projects plus their costs and implementation timeframe. Such detailed listing lifted the total value of investment under the SEQIPP to over \$32 billion (Australian) dollars (OUM 2005a). The scale of this sum in turn helped to signify the apparent seriousness with which the Queensland government was treating infrastructure questions.

A further indicator of the increasing significance of infrastructure planning in SEQ compared to land-use planning is the review cycle for the SEQIPP versus the SEQRP. While the SEQRP was intended to be reviewed every five years the SEQIPP receives a yearly review. At the time of writing the five-year review of SEQRP had been brought forward from 2010 to 2009 yet the SEQIPP had already seen two updates $(2007,2008)$ by mid-2008. Beyond their greater regularity the content of the SEQIPP updates further underscored the dramatic gain in importance of infrastructure planning in the region. First, the scale of the documentation had grown, from the 48 pages of the 2005 SEQIPP to the 108 pages of the 2008 update. In part this was because the scope of the plan had widened to cover not only transport, ports, information and communications technology, water, electricity and gas but also a broader range of infrastructure and facilities for community services such as health, primary, secondary and vocational education, emergency services, justice, sport and recreation facilities. Second, the scale of planned regional infrastructure spending over the period to 2026 had also escalated from \$32.2 billion to $\$ 107$ billion. Part this increase was a result of cost creep within a strong labour market but was also the result of new transport infrastructure projects such as a $\$ 7.5$ billion dollar Brisbane underground rail system as well as dramatic growth in water project funding from $\$ 861$ million in 2005 to almost $\$ 8$ billion in 2007, in response to severe drought conditions during 2004-2008. While land-use remained an important consideration under the SEQRP the sheer scale of the SEQIPP served to indicate the new and dramatic prominence of infrastructure.

\section{Brisbane's municipal 'infrastructure turn'}

The new significance of infrastructure in SEQ was also marked by the increasing prominence of the Brisbane City Council (BCC) as an initiator and sponsor of major projects. In 2004 a Liberal Party Lord Mayor - an engineer - was elected on an infrastructure platform organised around a set of five underground toll-road tunnels designed to support increased car traffic growth in inner Brisbane. The first of these 'Trans Apex' projects to enter the construction phase comprises a 4.2 kilometre road tunnel costing \$3 billion which is due for completion in 2010. A second road tunnel with a cost of $\$ 3.4$ billion is in the pre-construction phases while a third estimated at \$1.8 billion is in the investigation phase. That a municipal authority is embarking on such a massive scale infrastructure program is further demonstration of the importance of infrastructure in contemporary Australian metropolitan policy. The election of an engineer to the city's highest office further assists to accentuate this direction. The BCC example shows that infrastructure imperatives have taken hold not only at the spatial scale of state-led metropolitan planning but also at the local municipal scale. 


\section{Discussion - Australian Cities after the Infrastructure Turn}

The 'infrastructure turn' in Australian urban spatial strategy making and urban land-use planning raises considerable questions for planners in light of recent international experience. The introduction to this paper set out a number of these questions which have been illuminated through the three case studies presented above. This final section revisits these questions to assess the current condition and status of Australian planning, and planning internationally in a new phase of urban infrastructure.

The first question posed by this paper concerned the risks presented by a shift towards a heavy focus on infrastructure as the dominant means of planning and shaping urban outcomes. As the case study material has demonstrated the transition to an infrastructural urbanism or 'spatial engineering' limits questions of broader, comprehensive and strategic spatial and land-use planning in favour of a project-oriented engineering driven perspective. The history of urban planning in Australian and elsewhere records that a technocratic engineering focused approach to urbanisation has in the past paid insufficient attention to critical urban social, political and environmental processes (Jacobs 1961; Goodman 1972). In the absence of rigorous evaluation of the broader impacts of the new urban infrastructure in Australian cities, and elsewhere, urban policy risks the re-inscription of past failures on the urban fabric. Attempts to ignore, abolish or imagine away the functional and experiential complexities of place and space as a basic feature of cities via infrastructure almost inevitably result their its re-inscription on the urban fabric in unexpected and not necessarily desirable ways (Graham and Marvin 2001). While the immediate result may be the deployment of large functional monuments within the urban landscape, unless infrastructure policy is conceived within a clear strategic spatial comprehension of cities it risks creating new urban spatial problems that future spatial planners will be called upon to resolve.

The infrastructure turn also raises considerable questions about the capacity and legitimacy of urban planning as a spatial strategy, not least in Australian cities. It is now more than two decades since the intellectual and institutional capacity of planning to effect positive urban change was weakened by a broad shift in approach in which markets and private sector actors took on an increasing strategic spatial and land-use coordination role within cities. This was accompanied by a comparable shift in which the task of ensuring sufficient and efficient provision of urban infrastructure was progressively delegated to private agents. While the latter approach has been shown problematic and is now to be addressed through dedicated and intensive government investment programs the fragmented approach to planning has not yet received significant attention in Australia. While metropolitan spatial plans have emerged in recent years these have been relatively weak documents. The reach to infrastructure as a means of resolving urban problems indicates a governmental unwillingness to confront strategic urban spatial problems. If planning is not to be repaired under the 'infrastructure turn' then it risks revisiting another long period of relegation to a secondary policy concern - with little more than 'municipal dog-catcher' status (Mees 2003) - behind more conventional 
imperatives as efficiency and productivity and the promise that infrastructure claims for improving these factors.

A third risk from the 'infrastructure turn' is that the eclipse of spatial strategy making and metropolitan planning may obscure or distract attention from more effective institutional, governance means of achieving improved urban outcomes, including urban efficiency and productivity. There is a raft of evidence hinting that the governance arrangements in Australian cities, including those which manage urban infrastructure, may be inappropriate to their task. The case of Melbourne's public transport infrastructure is a good example with the independent scientific literature on this topic demonstrating that the privatisation experiment has failed and is now actively constraining improvements to the networks (Mees 2005). Similar problems of institutional impediments to improved efficiency are apparent in other jurisdictions. Such problems are unlikely to be resolved through infrastructure provision - their cause and solution is inevitably institutional and political. Following Winner's (1980) insights and Abrams (2005) reminder, the stressors afflicting the infrastructure artefacts of the Australian city are as likely to derive from politics as technics. Conceiving technics outside of politics may produce spectacular monumental urbanism - the city as giga-project - but spectacle is not necessarily efficient or productive. There is likely to be considerable scope in Australian cities for spatial planning to generate improved urban outcomes through more rigorous coordination and control, although this is unlikely to produce the same scale of spectacle, and immediate political payoff for its proponents, that assemblies of infrastructure megaprojects entail.

A fourth risk from the infrastructure turn is that it will exacerbate the economic, social and environmental 'splintering' of Australia's major urban regions in an era of climate concern and changing energy security. There is a growing, although yet incomplete, body of evidence, both in Australia and elsewhere that the past two decades of reliance on private actors for urban coordination and the fragmentation of urban governance have generated a range of social processes that have in turn produced undesirable urban effects such as social polarisation, marginalisation and exclusion (Graham and Marvin 2001). Similarly the splintering of cities around infrastructure has reduced urban 'coherence'. Planning faces a critical task of ensuring that the schemes upon which it embarks will reinforce the conceptual and empirical coherence of cities to avoid the potential for splintering of the urban realm and preserve the capacity to act on key strategic threats such as climate mitigation and deteriorating energy security. There is little indication that the contemporary Australian program is paying significant heed to such concerns.

This paper has argued that Australian urban planning has witnessed an infrastructure turn' in which a resurgence of interest in spatial strategy making and land-use planning has given way to a new and increasingly dominant focus on urban infrastructure as the key mechanism to shape urban outcomes. The paper has demonstrated this pattern via two metropolitan case studies. In Melbourne a highly prominent metropolitan strategy with prominent land-use components was overtaken via an incremental shift to infrastructure schemes as a primary urban intervention. In South East Queensland a landmark metro-regional spatial strategy with robust spatial land-use components has been eclipsed by a more expansive and heavily funded infrastructure plan. Rather than 
fulfilling their recent promise as exemplars of a new 'spatial strategy making' Australia's cities appear set to become the construction sites of an as yet poorly articulated 'spatial engineering' and all the uncertainties, ambiguities and dangers this technocratic revisioning implies.

\section{References}

Abram, S. (2005). "Science/technology as politics by other means." Focaal: The European Journal of Anthropology 46: 3-20.

ABS (2008). Melbourne: A social atlas 2006 Canberra, Australian Bureau of Statistics.

Albrechts, L., Alden, J. and Da Rosa Pires, A. (2001). The Changing Institutional Landscape of Planning. Aldershot, Ashgate.

Alford, J. and O'Neill, D., Eds. (1994). The Contract State: public management and the Kennett government. Geelong, VIC., Centre for Applied Social Research, Deakin University.

Atkinson, A. (2007). "Cities after oil-1: 'Sustainable development' and energy futures." City 11(2): 201213.

Baum, S. (1997). "Sydney, Australia: a global city? Testing the social polarisation thesis." Urban Studies 34(11): 1881-2003.

Birrell, B., O'Connor, K., Rapson, V. and Healy, E. (2005). Melbourne 2030: Planning Rhetoric versus Urban Reality. Sydney, Sydney University Press.

Brenner, N. (1999). "Globalisation as Reterritorialisation: The Re-scaling of Urban Governance in the European Union." Urban Studies 36(3): 431-451.

Buxton, M. and Goodman, R. (2003). "Protecting Melbourne’s Green Belt." Urban Policy and Research 21(2): 205-209.

Costar, B. and Economou, N., Eds. (1999). The Kennett Revolution: Victorian politics in the 1990s. Sydney, University of New South Wales Press.

Coutard, O., Ed. (1999). The Governance of Large Technical Systems. London and New York, Routledge.

Davidson, K. (2005). "Running down public transport." The Age, 24 February: 17.

Department of Infrastructure (2002). Melbourne 2030: Planning for Sustainable Growth. Melbourne, Department of Infrastructure.

Department of Infrastructure (2004). Linking Melbourne: Metropolitan Transport Plan. Melbourne, Department of Infrastructure.

Department of Transport (DOT) (2008). Investing In Transport: East West Link Needs Assessment. Melbourne, Victorian Government.

Dodson, J. (2003). "Visions for 2030: Housing and Transport Planning in Labor's Metropolitan Strategy." Visions for Victoria: Proposals to achieve public sector renewal in Australia. Hayward, D. and Ewer, P. Melbourne.

Dodson, J. and Gleeson, B. (2003). "New Planning Governance for Regional Sydney: Lessons from other contexts." Australian Planner 40(1): 32-39.

Dodson, J. and Sipe, N. (2007). "Oil vulnerability in the Australian city: Assessing socio-economic risks from higher urban fuel prices." Urban Studies 44(March): 37-62.

Flybvjerg, B., Bruzelius, N. and Rothengatter, W. (2003). Megaprojects and Risk: An anatomy of ambition. London and New York, Cambridge University Press.

Flyvbjerg, B. (2005). "Measuring inaccuracy in travel demand forecasting: methodological considerations regarding ramp up and sampling." Transportation Research Part A 29: 522-530.

Gleeson, B. (2003a). "Think smart to grow smart - opinion article." Courier Mail, 27 February: p. 15.

Gleeson, B. (2003b). "Travellers caught in government gridlock - opinion article." Courier Mail, 7 April: p. 13.

Gleeson, B., Darbas, T. and Lawson, S. (2004). "Governance, Sustainability and Recent Australian Metropolitan Strategies: A Socio-Theoretic Analysis." Urban Policy and Research 22(4): 345366. 
Gleeson, B. and Low, N. (2000). Australian Urban Planning: New challenges, new agendas. St Leonards, NSW, Allen and Unwin.

Gökalp, I. (1992). "On the Analysis of Large Technical Systems." Science, Technology and Human Values 17(1): 57-78.

Goodman, R. (1972). After the Planners. Harmondsworth, Penguin Books.

Goodman, R. and Coote, M. (2007). "Sustainable Urban Form and the Shopping Centre: An investigation of activity centres in Melbourne's growth Areas." Urban Policy and Research 25(1): 39-61.

Graham, S. (2000). "Constructing Premium Network Spaces: Reflections on Infrastructure and Contemporary Urban Development." International Journal of Urban and Regional Research 24(1): 183-200.

Graham, S. and Marvin, S. (2001). Splintering Urbanism: Networked infrastructures, technological mobiities and the urban condition. London and New York, Routledge.

Hall, P. (1998). Cities in Civilization. London, Pantheon Books.

Hall, P. (2002). Cities of Tomorrow: An intellectual history of Urban Planning and Design in the Twentieth Century. Oxford, Blackwell.

Harvey, D. (1989). "From Managerialism to Entrepreneurialism: the transformation in urban governance in late capitalism." Geografiska Annaler 71(B): 3-17.

Healey, P. (2004). "The Treatment of Space and Place in the New Strategic Spatial Planning in Europe." International Journal of Urban and Regional Research 28(1): 45-67.

Healey, P. (2006a). "Relational Complexity and the Imaginative Power of Strategic Spatial Planning." European Planning Studies 14(4): 525-546.

Healey, P. (2006b). Urban Complexity and Spatial Strategies: a relational planning for our times. London, Routledge.

Healey, P., Khakee, A., Motte, A. and Needham, B. (1999). "European Developments in Strategic Spatial Planning." European Planning Studies 7(3): 339-355.

Infrastructure Planning Council (2002). Final Report Part A: Overview and Recommendations. Melbourne, Victorian Government.

Jacobs, J. (1961). The Death and Life of Great American Cities. New York, Random House.

Kaika, M. and Swyngedouw, E. (2000). "Fetishizing the Modern City: The Phantasmagoria of Urban Technological Networks." International Journal of Urban and Regional Research 24(1): 120-138.

Kain, P. (2007). The pitfalls in competitive tendering: addressing the risks revealed by experience in Australia and Britain. Canberra, Bureau of Transport and Regional Economics.

Kearns, A. and Paddison, R. (2000). "New Challenges for Urban Governance." Urban Studies 37(5-6): 845-850.

Lefevre, C. (1998). "Metropolitan Government and Governance in Western Countries: A Critical Review." International Journal of Urban and Regional Research 22(1): 9-25.

Lewis, M. (1999). Suburban Backlash: The battle for the world's most liveable city. Melbourne, Bloomings Books.

Low Choy, D. (2003). "Plan with people power - opinion article." Courier-Mail, 20 June: 17.

Madanipour, A., Hull, A. and Healey, P. (2001). The Governance of Place: Space and planning processes. Aldershot, Ashgate.

McFarlane, C. and Rutherford, J. (2008). "Political Infrastructures: Governing and experiencing the fabric of the city." International Journal of Urban and Regional Research 32(2): 363-374.

McGuirk, P. (2003). "Producing the Capacity to Govern in Global Sydney: A multiscaled account." Journal of Urban Affairs 25(2): 201-233.

McGuirk, P. (2005). "Neoliberalist Planning? Re-thinking and Re-casting Sydney's Metropolitan Planning." Geographical Research 43(1): 59-70.

Mees, P. (2000). "From Philosopher-King to Municipal Dog-Catcher and Beyond." Urban Policy and Research 18(3): 377-386.

Mees, P. (2003). "Paterson's Curse: The attempt to revive metropolitan planning in Melbourne." Urban Policy and Research 21(3): np.

Mees, P. (2005). "Privatization of Rail and Tram Services in Melbourne: What Went Wrong?" Transport Reviews 24(4): 433-449.

Mitchell-Weaver, C., Miller, D. and Deal, R. (2000). "Multilevel Governance and Metropolitan Regionalism in the USA." Urban Studies 37(5-6): 851-876. 
Nankervis, M. (1996). "Living Suburbs Living Policy?: Some comments on Melbourne's Recent Metropolitan Planning Policy Document 'Living Suburbs'." Urban Policy and Research 14(1): 6567.

O'Connor, K. (2003). "Melbourne 2030: A Response." Urban Policy and Research 21(2): 211-215.

Office of Urban Management (2005a). South East Queensland Infrastructure Plan and Program 20052006. Brisbane, Office of Urban Management, Queensland Government.

Office of Urban Management (2005b). South East Queensland Regional Plan 2005-2006. Brisbane, Office of Urban Management, Queensland Government.

Paterson, J. (2000). "Choice and Necessity in Urban Planning." Urban Policy and Research 18(3): 377386.

Salet, W., Thornley, A. and Kreukels, A., Eds. (2002). Metropolitan Governance And Spatial Planning : Comparative Case Studies Of European City-regions. London and New York, Spon Press.

Sandercock, L. and Friedman, J. (2000). "Strategising the Metropolis in a Global Era." Urban Policy and Research 18(4): 529-533.

SEQROC (2000). Regional Framework for Growth Management. Brisbane, South East Queensland Regional Organisation of Councils.

Silkstone, D. (2005). "How to fix Melbourne's woes." The Age, 12 November: 9.

Sipe, N. and Gleeson, B. (2003). "Coordinate or stagnate - opinion article." Courier-Mail, 18 September: 15.

Star, S. L. (1999). "The Ethnography of Infrastructure." American Behavioural Scientist 43(3): 377-391.

Tarr, J. and Dupuy, G., Eds. (1988). Technology and the Rise of the Networked City in Europe and America. Philadephia, Temple University Press.

Torrance, M. I. (2008). "Forging Glocal Governance? Urban Infrastructures as Networked Financial Products." International Journal of Urban and Regional Research 32(1): 1-21.

Williams, G. (1999). "Metropolitan governance and strategic planning: a review of experience in Manchester, Melbourne and Toronto." Progress in Planning 52(1-100).

Winner, L. (1980). "Do Artifacts Have Politics?" Daedalus 109(1): 121-136. 